\title{
Do the Innovation Index of the Regions and the Sectors of Belonging Affect the Performance of the ASOs?
}

\author{
Margaret Antonicelli ${ }^{2}$ \& Ivano De Turi, ${ }^{1,2}$ \\ ${ }^{1}$ Lum Jean Monnet University, Bari, Italy \\ ${ }^{2}$ School of Management, Lum Jean Monnet University, Bari, Italy \\ Correspondence: Ivano De Turi Lum, Jean Monnet University, Casamassima (Bari), Italy.
}

Received: July 7, 2020

doi:10.5539/ibr.v13n9p113
Accepted: August 7, 2020

Online Published: August 20, 2020

URL: https://doi.org/10.5539/ibr.v13n9p113

\begin{abstract}
The considerable economic contribution of academic spin-offs (ASOs) has drawn numerous scholars' attention to explore the factors that influence their development (Hossinger, 2020). The growing attention on these issues has led researchers to investigate the drivers and success factors that have the greatest impact on the performance of ASOs.This paper has been designed with a dual purpose. On the one hand, the document aims to examine how much a region's innovation index reflects positively on the performance of ASOs. On the other hand, the paper also examines in which sectors the impact of innovation on the performance of ASOs emerges most. The research hypotheses of these paintings were explored in an empirical study of 1,007 Italian spin-offs over a time range from 2010 to 2019. To carry out the analysis, a panel model with fixed effects was used, with an unbalanced dataset.
\end{abstract}

Keywords: innovation, entrepeneurship, technology transfer, econometric approach, panel model, academic spin-off

\section{Introduction}

\subsection{Introduce the Problem}

In recent years, the role of universities has become increasingly central to local economic growth. This has been widely identified as a strategy to involve more entities and companies interested in technology transfer processes (Zucker et al. 1998; Di Gregorio and Shane 2003) and to create the conditions for the capitalization of intellectual property and academic research (Goldstein 2010). The creation of new business entities, in the form of academic spin-offs (ASOs), is an effective way for universities to contribute to local development in response to the lack of financial resources by cooperating with private companies (Cohen et al. 1998). ASOs have increasingly acquired recognition as efficient engines of regional and national competitiveness thanks to their potential ability to foster economic activity (Nicolaou and Birley 2003) and create a link between businesses and universities (Debacker and Veugelers 2005; Perez and Sánchez 2003). Pursuing the territorial development objective is strongly linked to the ability of local institutions to create a fertile environment for contamination between public and private entities with the same purpose territorial competitiveness (De Turi, 2019). The first scientific contributions elaborated on the third mission of universities date back to the early 1970s when we started talking about mission-oriented research in education (Stockton, 1970). Subsequently it acquired the name of third-mission from the 80s (Gollattscheck, 1983) until it was consolidated in the late 90s when it made express reference to the connection between technology transfer, entrepreneurship and territorial competitiveness (Etzkowitz \& Leydesdorff, 1998). At a territorial level, the ability to feed and capitalize on the results of research in business projects capable of generating good performances in economic terms depends very much on the role of the policies and the competitive context present in the reference region. The presence of facilitators (business incubators, business accelerators, technology parks, etc.) certainly makes the difference on the performance of ASOs (De Turi \& Antonicelli, 2019).

\subsection{State Hypothesy and the Correspondence to Research Design}

In light of the centrality of the external environment in the process of growth of the academic spin-offs and after detecting the elements that have the greatest impact on the economic performance of the ASOs, in this work the attention will be focused on the performance of the Italian spin-offs trying to investigate, on several levels, on 
the role of local policies and localization.

Specifically, by crossing information relating to the performance of ASOs in single regions and the related information in terms of innovation index, we will try to identify which regions have most created an economic environment capable of fueling the growth processes of academic spi-offs.

Based on statements like these just reported, actually to the research hypothesis, the present study will develop on the following hypothesis:

- H1: Is there a connection between the geographical area of belonging and the performance of the Asos? Regarding to this hypotesys, we want to affirm that the relationship is positive and statistically significant

- H2: Does the innovation index of the regions reflect on the performance of the ASOs? As the difference of innovation between the Italian regions is marked, in this study we want to demonstrate that this link is positive and statistically significant

- H3: Are there any sectors that are most affected by the innovation index of the regions in which they are located? The propensity for this to want to be strongly inclined towards innovation both in terms of process and in terms of product is physiologically intrinsic to the nature of a company. Starting from this consideration, through the study we want to test and affirm the relationship between these components and, in particular, the hypothesis in question hypothesizes a statistically significant and positive relationship.

\section{The Role of Policy Makers in a Rapidly Changing Business World}

The context of Italian SMEs is increasingly becoming aware of the fact that creating easily replicable goods does not generate the same value that was generated before, and that education, creativity, inventiveness, knowing how to combine "artisan knowledge" and ability innovative, they are key ingredients to increase competitiveness by positioning itself in the highest segments of the world market, thus guiding the country on a path of lasting and sustainable growth. The policies implemented in recent years have tried to accompany these processes of change. Their main objective was in fact to encourage the transition from an economy to a manufacturing center of gravity to an economy in which research and development, innovation, digital technology and all the services that gravitate around industry can take on an increasingly strategic role. An attempt was therefore made to adapt industrial policy to the new needs expressed by the market, accompanying it and integrating it increasingly within a framework of interventions aimed at supporting industrial research. The dialogue between administrations and public and private bodies in charge of industrial policies and policies for R\&D and innovation (MIUR, MISE, first of all), as reported in many studies, has become essential. This need is increasingly leading to experimenting models of collaborations and consultations, in line with the objectives set by the EU. Following therefore the indications of the European Commission, which urges member states to a more effective coordination aimed at promoting excellence and territorial vocations, avoiding fragmentation and overlapping (S3, smart specialization strategy), our policy makers are increasingly committed - at various institutional levels, with representative companies / associations and with qualified bodies for R\&D and innovation - in the definition of policy tools that have a real response with the territorial vocations and with the real needs of our production fabric (Altobelli, Carnazza, 2015). The formulation of effective innovation policy lines - be they national, regional / local or sectoral - requires upstream a systemic vision of the networks of public and private institutions involved in various ways in R\&D and innovation processes and a representation complete with their structure, typologies, functions and interconnecting links. To this end, the prevailing approach at international level is that of the so-called national research and innovation systems (NIS), which represent the conceptual reference within which the institutions that deal with the generation, application and dissemination of scientific knowledge must be placed. and technology within each country. In particular, regional innovative forms differ not only based on specific strategies and technological performance within companies, but also based on external and contextual elements favorable to innovation and systemic interactions. Ultimately, the need to consider the overall system is due to the fact that there is no direct correlation between input (volume of R\&D) and output (innovations introduced on the market): the effectiveness of the process of transforming knowledge into concrete innovation depends by the structure of the system, that is, by the completeness of the institutions necessary for its proper functioning and by the intensity and correctness of the existing ties (Galli, 2010). The relationships that are created between the innovation players at local, regional and national levels contribute to the creation of a profitable environmental context for the indirect improvement of business performance. 


\section{Empirical Analysis}

\subsection{Sample}

The sample on which this study is based sees the questioning of the platform Spin-off Italy for the identification of the Italian spin offs. The 1007 spin-offs in Italy from 2010 to 2019 were screened. The Italian platform used for research is, the only Italian portal containing updated information on the spin-offs of Italian public research (De Turi, Antonicelli, 2020). Through the portal, it was possible to obtain detailed information on the characteristics of the spin-offs, both at the registry level and at the economic-financial level. Based on the nature of the research in question, the database most used in this study was Aida Bureau Van Dijk. Furthermore, this information was implemented by additional data extracted from the European Commission platform. For the purposes of econometric research, it was decided to consider only the Italian spin-offs of public research currently active; for our final representative sample of the phenomenon of academic spin-offstherefore, from our reference sample, it was necessary to eliminate the companies registered on the dataset as discontinued or in liquidation ((De Turi, Antonicelli, 2020).

\subsection{Methodology}

In this study it was performed a fixed panel model. The data in panel format combine information relating to the characteristics of $\mathrm{N}$ individuals in it temporal instant with those detected for the same individuals in different $\mathrm{T}$ periods of time. In type models panel the available data therefore have both characteristics of:

- Cross Section Data: for a given moment the characteristics of multiple individuals are observed;

- Time Series data: for a given collective of individuals the different characteristics are detected in different moments.

$$
\underset{(N \times T)}{Y}=\left[\begin{array}{cccccc}
y_{11} & y_{21} & \ldots & y_{i 1} & \ldots & y_{N 1} \\
y_{12} & y_{22} & \ldots & y_{i 2} & \ldots & y_{N 2} \\
\vdots & \vdots & & \vdots & & \vdots \\
y_{1 t} & y_{2 t} & \ldots & y_{i t} & \ldots & y_{N t} \\
\vdots & \vdots & & \vdots & \ddots & \vdots \\
y_{1 T} & y_{2 T} & \ldots & y_{i T} & \ldots & y_{N T}
\end{array}\right]
$$

Since the cross section and time series data each have their own peculiarities, they carry with them all the complications above all as regards the disappearance of some classical hypotheses of the model linear regression.

$$
\mathrm{Y}=\mathrm{X} \beta+\varepsilon
$$

Through (2) it is possible to introduce the notation. The vector $\mathrm{Y}$ of dimension $(\mathrm{NT} \times 1)$ is obtained applying the vec operator to the matrix (1) and represents the dependent variable, the matrix of the regressors $\mathrm{X}$ has dimension $(\mathrm{NT} \times \mathrm{k}$ ), while the $\mathrm{k}$-dimensional vector $\beta$ contains the unknown parameters to be estimated. The term disturbance $\varepsilon$ has the same dimensions as the dependent variable.

When we discuss about longitudinal data we mean a structure like the one illustrated by the matrix (1) in the which generally the number of individuals is high, while that relating to the temporal dimension is rather contained.

Note that if the assumptions about the variance and covariance matrix $\Omega$ and the constant (if any) respect those of the pooled time series models, they automatically become can be used in this context simply by exchanging indices relating to individuals and time (De Turi, Antonicelli, 2019).

Considering the $\mathrm{i}$-th individual, the fixed effects model is configured as follows

$$
\mathrm{y}_{\mathrm{i}}=\alpha_{\mathrm{i}}+\beta \mathrm{x}_{\mathrm{i}}+\varepsilon_{\mathrm{i}}
$$


Where yi and $\varepsilon i$ have dimension $(T \times 1)$, xi has dimension $(T \times k)$ and $\beta$ is the vector containing $k$ parameters from to estimate (De Turi, Antonicelli, 2019). The peculiarity of this function concerns the constant which is configured as a vector of $\mathrm{T}$ constant elements equal to $\alpha \mathrm{i}$ : this characteristic indicates first of all that for each individual only one value has to be estimatedof the constant and that, if $\alpha_{i} \neq \alpha_{j}$ for every $i \neq j$, this constant measures the individual effect, i.e. that set specific characteristics of each individual which however remain unchanged over time. In practice, in model there are in all $\mathrm{k}+\mathrm{N}$ parameters to estimate, $\mathrm{k}$ contained in the vector $\beta$ and $\mathrm{N}$ constants for the different ones individuals. These constants represent the characteristic heterogeneity between individuals in the system peculiar to panel data (De Turi, Antonicelli, 2019).

By generalizing the function described above, rewriting it in matrix form, it is possible to write

$$
\left[\begin{array}{c}
y_{1} \\
y_{2} \\
\vdots \\
y_{N-1} \\
y_{N}
\end{array}\right]=\left[\begin{array}{ccccc}
\iota_{T} & 0 & \ldots & 0 & X_{1} \\
0 & \iota_{T} & \ldots & 0 & X_{2} \\
\vdots & \vdots & \ddots & \vdots & \vdots \\
0 & 0 & \ldots & 0 & X_{N-1} \\
0 & 0 & \ldots & \iota_{T} & X_{N}
\end{array}\right]\left[\begin{array}{c}
\alpha_{1} \\
\alpha_{2} \\
\vdots \\
\alpha_{N} \\
\beta
\end{array}\right]+\left[\begin{array}{c}
\varepsilon_{1} \\
\varepsilon_{2} \\
\vdots \\
\varepsilon_{N-1} \\
\varepsilon_{N}
\end{array}\right] \text {, }
$$

where $\mathrm{\imath T}$ is a vector containing $\mathrm{T}$ elements equal to 1 . In compact form we have therefore

$$
Y=\left[\left(\begin{array}{ll}
\left(I_{N} \otimes \iota_{T}\right) & X
\end{array}\right]\left[\begin{array}{l}
\alpha \\
\beta
\end{array}\right]+\varepsilon\right.
$$

or

$$
\underset{(N T \times 1)}{Y}=\underset{(N T \times N)}{\left(I_{N} \otimes \iota_{T}\right)} \underset{(N \times 1)}{\alpha}+\underset{(N T \times k)(k \times 1)}{X} \underset{(N T \times 1)}{\beta}
$$

Since the values of the vector $\alpha$ are not observable they would fully enter the error of the model but, if so, they could be correlated with the explanatory variables $\mathrm{Xi}$ and the estimate would result distorted.

This function allows you to estimate the model through the OLS as all the classic hypotheses are respected. The model is called a dummy variable model because it is necessary to construct $\mathrm{N}$ (nuerosity) of individual effects) dummy variables to be inserted within the regressors matrix. The estimator you are gets undistorted, consistent and BLUE. Given that for the properties of the product of Kronecker it holds

$$
(\mathrm{IN} \otimes \imath \mathrm{T})^{\prime}(\mathrm{IN} \otimes \imath \mathrm{T})=\mathrm{IN} \otimes \imath^{\prime} \mathrm{T} \imath \mathrm{T}=\mathrm{T} \mathrm{IN}
$$

it turns out

$$
\left[\begin{array}{c}
\hat{\alpha} \\
\hat{\beta}
\end{array}\right]=\left[\begin{array}{cc}
T I_{N} & \left(I_{N} \otimes \iota_{T}\right)^{\prime} X \\
X^{\prime}\left(I_{N} \otimes \iota_{T}\right) & X^{\prime} X
\end{array}\right]^{-1}\left[\begin{array}{c}
\left(I_{N} \otimes \iota_{T}\right)^{\prime} Y \\
X^{\prime} Y
\end{array}\right] .
$$

To invert the matrix contained within the expression of the OLS estimator, a known result is used on partitioned matrices and, after some calculations you get to

$$
\left[\begin{array}{c}
\hat{\alpha} \\
\hat{\beta}
\end{array}\right]=\left[\begin{array}{c}
\frac{1}{T}\left(I_{N} \otimes \iota_{T}\right)^{\prime}(Y-X \hat{\beta}) \\
\left(X^{\prime} M X\right)^{-1} X^{\prime} M Y
\end{array}\right],
$$

where $\mathrm{M}=\mathrm{INT}-\mathrm{P}$ is the projection matrix which, applied to a variable, for each individual returns lo deviation from the time arithmetic mean. This matrix, by definition, turns out to be square $(\mathrm{NT} \times \mathrm{NT})$, diagonal block, 
symmetrical and idempotent.

Taking into account the estimator $\beta^{\wedge}$ determined in equation (9) and keeping in mind the property of idempotency of the matrix M occurs

$$
\begin{aligned}
\hat{\beta} & =\left(X^{\prime} M X\right)^{-1} X^{\prime} M Y \\
& =(\dot{X} \dot{X})^{-1} \dot{X} \dot{Y}
\end{aligned}
$$

This estimator is therefore obtainable also through the OLS regression of $\mathrm{Y}^{*}=\mathrm{MY}$ on $\mathrm{X}^{*}=\mathrm{MX}$; in practice it comesapplied the classic linear model where both the dependent variable and the matrix of the regressors are expressed in deviation from the corresponding individual averages calculated with respect to time.

The $\beta^{\wedge}$ estimator therefore takes the name of Within Estimator as it takes into account the individual effects

thanks to the transformation carried out through the matrix M, but eliminates them from the model using for each we identify the information deriving from temporal variations (variations "in groups").

The within estimator and the dummy variable estimator always produce the same numeric values. Once the within estimator is obtained, the individual effects excluded from its calculation can be exploited through equation (8), in fact

$$
\begin{aligned}
& \left(I_{N} \otimes \iota_{T}\right) \alpha=Y-X \hat{\beta} \\
& \frac{1}{T}\left(I_{N} \otimes \iota_{T}\right)^{\prime}\left(I_{N} \otimes \iota_{T}\right) \alpha=\frac{1}{T}\left(I_{N} \otimes \iota_{T}\right)^{\prime}(Y-X \hat{\beta}) \\
& \frac{1}{T}\left(I_{N} \otimes \iota_{T}^{\prime}\right)\left(I_{N} \otimes \iota_{T}\right) \alpha=\frac{1}{T}\left(I_{N} \otimes \iota_{T}\right)^{\prime}(Y-X \hat{\beta}) \\
& \frac{1}{T}\left(I_{N} \otimes T\right) \alpha=\frac{1}{T}\left(I_{N} \otimes \iota_{T}\right)^{\prime}(Y-X \hat{\beta}) \\
& \hat{\alpha}=\frac{1}{T}\left(I_{N} \otimes \iota_{T}\right)^{\prime}(Y-X \hat{\beta}) .
\end{aligned}
$$

Equation (11) shows that, for each individual, the constant is equal to the difference between the individual average of the dependent variable and the individual means of the regressors weighted by the within estimator. From the point of view of the individual, analytically we have

$$
\hat{\alpha}_{i}=\bar{y}_{i}-\bar{x}_{i} \hat{\beta}
$$

The constants $\alpha \mathrm{i}$ with $\mathrm{i}=1,2, \ldots, \mathrm{N}$ capture the effect of those variables that vary between individual and individual, but they remain unchanged over time; therefore the within estimator takes into account only the heterogeneity between individuals. The most obvious limitation of this approach consists in the impossibility of including regressors in the model assume a constant value within the observations relating to the individual: from the point of view statistical, this impossibility derives from the fact that an explanatory variable with this characteristic would result collinear with (IN $\otimes \mathrm{iT}$ ) in equation (8), while from an algebraic point of view calculate the deviation of these variables by their individual mean value (through the matrix $\mathrm{M}$ ) would produce columns of zeros in the matrix of regressors who therefore would not have full rank. In this case the OLS method would therefore not be applicable.

For the verification of hypotheses relating to the absence of heterogeneity between individuals, the zero test of the constants $\alpha \mathrm{i}$ is of no practical use. Instead it is possible to build a test ' $\mathrm{F}$ in which the null hypothesis is $\mathrm{H} 0$ : $\alpha 1=\alpha 2=\ldots=\alpha \mathrm{N}(\mathrm{N}-1$ constraints in all $)$; the test statistic is

$$
\frac{\tilde{\varepsilon}^{\prime} \tilde{\varepsilon}-\hat{\varepsilon}^{\prime} \hat{\varepsilon}}{\hat{\varepsilon}^{\prime} \hat{\varepsilon}} \cdot \frac{N T-N-K-1}{N-1} \sim F_{N-1, N T-N-K-1},
$$

where $\tilde{\varepsilon}$ and ${ }^{\wedge} \varepsilon$ are the residuals of the constrained and free models respectively, while the correct estimator and consistent for the variance is 


$$
\hat{\sigma}_{\varepsilon}^{2}=\frac{\hat{\varepsilon}^{\prime} \hat{\varepsilon}}{N T-N-K-1} .
$$

Considering this we also have $\mathrm{V}$ ar $\left(\beta^{\wedge}\right)={ }^{\wedge} \sigma_{\varepsilon}^{2}\left(\mathrm{X}^{\prime} \mathrm{MX}\right)^{-1}$. Finally, note that, under H0, in fact lo within estimator coincides with the pooled estimator.

The estimator within is

- BLUE,

- consistent for NT $\rightarrow \infty$,

- asymptotically normal since it is

$$
\sqrt{N T}(\hat{\beta}-\beta) \stackrel{\mathrm{d}}{\longrightarrow} N\left(0, \sigma_{\varepsilon}^{2} Q^{-1}\right),
$$

where

$$
Q=\lim _{N T \rightarrow \infty}\left(\frac{1}{N T} X^{\prime} M X\right)^{-1}
$$

\subsection{Results and Discussion}

The object of the analysis, as well as the dependent variables of our model, are represented by the income and productivity of the employees. Through these variables, we want to investigate how much these business aspects are determined and influenced by the identified regressors.

Specifically, the variables analyzed are:

- REVENUE, indicates in thousands of euro the average amount of economic utility that an enterprise achieves in its sales and services;

- EMPLOYEES PRODUCTIVITY, measures the efficiency of the production process, given by the relationship between output and input ( $\rightarrow$ production factor);

- REGIONAL INNOVATION SCOREBOARD, is a comparative assessment of regional innovation based on the European innovation scoreboard methodology, using 18 of the latter's 27 indicators

- EMPLOYEES, expresses the average number of employees assigned during the three-year period;

- EBITDA, gross operating profit expressed in thousands of euros, the income from the operational management of a company excluded from the calculation of the financial decisions and the tax context;

- OPERETING PROFIT, is the difference between a company's revenues and costs is indicated. If this difference is positive, it is commonly called profit or surplus or surplus, otherwise it is called loss or deficit or deficit;

- ROI, is a balance sheet index that indicates the profitability and economic efficiency of the characteristic management regardless of the sources used: that is, it expresses how much the capital invested makes;

- ROS, represents the average operating result per unit of revenue. This ratio expresses the company's profitability in relation to the remunerative capacity of the revenue stream;

- ROE, return on equity capital expressed as a percentage of the ratio between Net Income and Equity;

- GDP pro capita regional is calculated by comparing the GDP expressed at market prices to the population residing in the region.

The Dummy variables taken into consideration are:

- ZONE, used to indicate the geographical area in which the company is located, it takes on value 1 if it is located in the Islands, 2 in the South, 3 in the Center, 4 if it is located in the North-East and finally 5 in the Northwest; 
- SECTOR, used to indicate the economic sector of reference, assumes value 1 in the case the activity is inherent in Agriculture / Fishing, 2 in the case of Industry and IOT / Crafts, 3 for Services, 4 for Trade and finally 5 if it operates in Tourism;

In the first analysis, we proceeded with the study of descriptive statistics and the correlation matrix. Regarding to the approach, it was decided to insert a classical structure of the descriptive statistics rather than the panel approach which provides for the analysis of different indicators with overall structures (which coincides with what was declared) between and within. This was possible because there were no significant differences among the different approaches (De Turi, Antonicelli, 2019). In these analyzes, dichotomous variables were excluded.

The study consists of two phases: a first descriptive statistical approach and econometric analyzes will be performed with fixed effect panel approaches. With regard to the first component of the study, we proceeded to the study of descriptive statistics and the correlation matrix. As for the approach, it was decided to insert a classical structure of descriptive statistics instead of the panel approach, which provides for the analysis of different indicators with overall structures (which coincides with what has been declared) between and within. This was possible because there were no significant differences between the different approaches. In these analyzes, dichotomous variables were excluded (De Turi, Antonicelli, 2019).

Table 1. Descriptive statistics and correlation matrix

\begin{tabular}{|c|c|c|c|c|c|c|c|c|c|c|c|c|c|}
\hline \multicolumn{2}{|c|}{ Variables } & Mean & SD & 1 & 2 & 3 & 4 & 5 & 6 & 7 & 8 & 9 & 10 \\
\hline 1 & Revenues & 327.30 & 7.22 & 1 & & & & & & & & & \\
\hline 2 & RIS** & 125.91 & 9.34 & $0.78 *$ & 1 & & & & & & & & \\
\hline 3 & EBITDA & 22.56 & 39.15 & 0.87 & $0.78 *$ & 1 & & & & & & & \\
\hline 4 & Employees & 3.45 & 3.04 & $-0,37 *$ & $-0.67 *$ & -0.22 & 1 & & & & & & \\
\hline 5 & ROI & 2.37 & 8.34 & 0.28 & $0.42 *$ & $0.29 *$ & 0.31 & 1 & & & & & \\
\hline 6 & ROE & 4.87 & 5.45 & $0.29 *$ & 0.21 & 0.38 & -0.09 & 0.34 & 1 & & & & \\
\hline 7 & ROS & 7.34 & 2.28 & -0.26 & $-0.19 *$ & -0.29 & 0.11 & $-0.01 *$ & -0.19 & 1 & & & \\
\hline 8 & $\begin{array}{l}\text { Employees } \\
\text { Productivity }\end{array}$ & 32.45 & 9.45 & $0.31 *$ & 0.76 & $0.75^{*}$ & $0.23 *$ & 0.15 & 0.12 & 0.21 & 1 & & \\
\hline 9 & $\begin{array}{l}\text { Opereting } \\
\text { Profit }\end{array}$ & -19.45 & 31.23 & -0.09 & -0.21 & $-0.09 *$ & 0.11 & $0.00^{*}$ & $-0.13 *$ & 0.34 & -0.19 & 1 & \\
\hline 10 & $\begin{array}{l}\text { GDP per } \\
\text { capita }\end{array}$ & 273.87 & 9.45 & 0.12 & 0.56 & 0.45 & $0.37 *$ & 0.23 & 0.11 & $0.37 *$ & 0.67 & 0.09 & 1 \\
\hline
\end{tabular}

*p-value $<0.001$

\section{**Regional Innovation Scoreboard}

Table 1 illustrates the descriptive statistics anda the correlation matrix for all variables for which there are no anomalies or statistics problems. All variables were analysed following the classic approach adopted for panel or multilevel analysis, for all observed variables, the analysis values shows the inexistence of outliers. Instead, as regards the standard deviation it is possible to observe how very similar values emerge from the overall and between approaches. This confirms a substantial condition of homogeneity both at the overall level and between countries. The same situation is also evident in the overall and between analysis applied to the minimum and maximum values. Furthermore, the standard deviation values, obtained performing the within approach, are lower than the other types of standard deviation. Moreover, the low values indicate there are no exogenous events that have altered the trend of the analysed variables. Regarding to the correlation matrix values the non-existence of high correlation values confirms, in the model, the possibility of coexistence of all the selected variables. Finally, the Variance Inflation Factor (VIF) test was carried out that confirms the absolute absence of multicollinearity since values less than 10 emerged for all the independent and control variables (Myers, 1990).

Tables 2 and 3 illustrate the result of multiple regression fixed effect models.

In the first case, the three models developed see sales revenues as the dependent variable, while in the second case the 3 models developed see sales employees productivity as the dependent variable 
Table 2. Multiple Fixed effect Models

\begin{tabular}{llll}
\cline { 1 - 3 } Dependent Variable & \multicolumn{3}{c}{ Revenues } \\
\cline { 2 - 3 } & 1 & 2 & 3 \\
\hline RIS & $0.89^{* * *}$ & $0.67^{*}$ & 0.34 \\
EBITDA & $2.54^{* *}$ & $4.12^{* *}$ & $1.78^{*}$ \\
Employees & $-0.34 *$ & $-0.76^{* *}$ & $-0.97 * *$ \\
ROI & $2.45^{*}$ & $0.98^{*}$ & $0.23^{*}$ \\
ROE & $1.43^{* * *}$ & $0.65^{* *}$ & $0.34^{*}$ \\
ROS & 3.56 & 0.11 & 0.23 \\
Employees Productivity & $0.98^{*}$ & $0.77^{*}$ & $0.37^{*}$ \\
Operating Profit & 2.56 & $5.34 *$ & $8.45^{* *}$ \\
GDP regional & $1.43^{* * *}$ & $3.44^{*}$ & $2.65^{*}$ \\
Industry and ICT & & $231.65^{* * *}$ & \\
Service & & $32.15^{*}$ & \\
Nord East & & & $56.32 * * *$ \\
Nord West & & & $43.54^{*}$ \\
Center & & & $26.35^{*}$ \\
Years & & & YES \\
& & YES & \\
R-squared & 0.67 & 0.71 & 0.79 \\
\hline
\end{tabular}

Regarding to the first three models, in which we have set "revenues" as the dependent variable. All regressors are, in most cases, statistically significant; moreover, the coefficients obtained, in terms of the type of impact on the dependent variable, are in agreement with the relative scientific literature.

As far as the validity of the performed models is concerned, all of them have excellent $R^{2}$ with values never lower than 0.65 .

Table 3. Multiple Fixed effect Models

\begin{tabular}{llll}
\hline \multirow{2}{*}{ Dependent Variable } & \multicolumn{3}{c}{$\begin{array}{c}\text { Employees } \\
\text { Productivity }\end{array}$} \\
\cline { 2 - 4 } & 1 & 2 & 3 \\
\hline RIS & $0.17^{* *}$ & $0.34^{* *}$ & $0.15^{*}$ \\
EBITDA & $2.11^{*}$ & $3.45^{*}$ & $2.03^{* *}$ \\
Employees & $0.98^{* * *}$ & $1.04^{* *}$ & $2.05^{*}$ \\
ROI & $1.41^{* *}$ & 0.83 & $1.37^{* *}$ \\
ROE & 0.87 & $0.75^{*}$ & $0.74^{* *}$ \\
ROS & $4.01^{*}$ & 0.24 & $0.51^{*}$ \\
Revenue & $2.43^{* *}$ & $1.67^{*}$ & $1.09^{*}$ \\
Operating Profit & 2.34 & $4.98^{* *}$ & $6.45^{* * *}$ \\
GDP regional & $1.71^{* *}$ & $2.76^{* *}$ & $3.02^{* *}$ \\
Industry and ICT & & $178.54^{* *}$ & \\
Service & & $16.43^{* *}$ & \\
Nord East & & & $38.28 * *$ \\
Nord West & & & $21.56^{* *}$ \\
Center & & & $15.24^{*}$ \\
Years & & & YES \\
& & & \\
R-squared & & & \\
\hline
\end{tabular}

On the other hand, with regard to the subsequent models, in which we set "worker productivity" as the dependent variable, also in this case all the regressors are, in most cases, statistically significant; moreover, the coefficients obtained, in terms of type of impact on the dependent variable, appear to be in agreement with the cited scientific literature. Moreover, regarding to the dummy variables, the sector and the geographical area are extremely important for our analysis. In particular, as far as the sector is concerned, as previously stated, industry and ICT are driving forces with regard to company profitability and employee productivity.

With regard to the $\mathrm{R}$ squared, in these models the index is higher and, consequently, thanks to the important contribution of the inserted dummy variables, the explained variance is over $70 \%$.

\section{Conclusion}

With regard to the geographical aspect, the north-eastern Italian area is a driving force in terms of profitability 
and productivity linked to technological innovation. Starting from the dummy variables, the sector and the geographical area are extremely important for our analysis. In particular, as far as the sector is concerned, as previously stated, industry and ICT are driving forces with regard to company profitability and employee productivity.

With regard to the geographical aspect, the north-eastern Italian area is a driving force in terms of profitability and productivity linked to technological innovation.

Relatively to the regressors, these, coherently with the literature, respond to the two dependent variables in a more than optimal way with values in almost all cases statistically significant.

\section{References}

Altobelli, C., \& Carnazza, P. (2015). L'evoluzione del sistema dell'innovazione in Italia tra norme, incentivi e nuove opportunità in Rivista Argomenti. Univerista' di Urbino, n 1/2015.

Cohen, W. M., Florida, R., Randazzese, L., \& Walsh, J. (1998). Industry and the academy: Uneasy partners in the cause of technological advance. In R. Noll (Ed.), Challenges to research universities (pp. 171-199). Washington, DC: Brookings Institution Press.

De Turi (2019). L'impatto dell'Innovation network sulle performance delle spin-off accademiche italiane. Cacucci Editore. ISBN: 9788866118183.

De Turi, I., \& Antonicelli, M. (2019). Can the External Environment Generate Better Economic Performance in Academic Spin-Offs? International Business Research. https://doi.org/10.5539/ibr.v12n11p30

Debacker, K., \& Veugelers, R. (2005). The role of academic technology transfer organizations in improving industry science links. Research Policy, 34(3), 321-342. https://doi.org/10.1016/j.respol.2004.12.003

Di Gregorio, D., \& Shane, S. (2003). Why do some universities generate more start-ups than others? Research Policy, 32(2), 209-227. https://doi.org/10.1016/S0048-7333(02)00097-5

Etzkowitz, H., \& Leydesdorff, L. (1998). "The endless transition: a 'triple helix' of university-industry-government relations: Introduction. Minerva, 36(3), 203-208. https://doi.org/10.1023/A:1004348123030

Galli, R. (2010). Sistemi nazionali dell'innovazione: modelli empirici per far crescere le imprese.

Goldstein, H. A. (2010). The 'entrepreneurial turn' and regional economic development mission of universities. Ann Reg Sci, 44(83). https://doi.org/10.1007/s00168-008-0241-z

Gollattscheck, J. F. (1983). All Things to All People? The Third Mission of the Community College. Community Services Catalyst, 13(1), 4-10.

Nicolaou, N., \& Birley, S. (2003). Academic networks in a trichotomous categorisation of university spinouts. Journal of Business Venturing, 18(3), 333-359. https://doi.org/10.1016/S0883-9026(02)00118-0

Perez, M. P., \& Sánchez, A. M. (2003). The development of university spin-ofs: Early dynamics of technology transfer and networking. Technovation, 23(10), 823-831. https://doi.org/10.1016/S0166-4972(02)00034-2

Stockton, R. (1970). Research Management: A University Position. American educational Research Association, Washington, D.C., ERIC.

Zucker, L. G., Darby, M. R., \& Armstrong, J. (1998). Geographically localized knowledge: Spillovers or markets? Economic Inquiry, 36(1), 65-86. https://doi.org/10.1111/j.1465-7295.1998.tb01696.x

\section{Copyrights}

Copyright for this article is retained by the author(s), with first publication rights granted to the journal.

This is an open-access article distributed under the terms and conditions of the Creative Commons Attribution license (http://creativecommons.org/licenses/by/4.0/). 